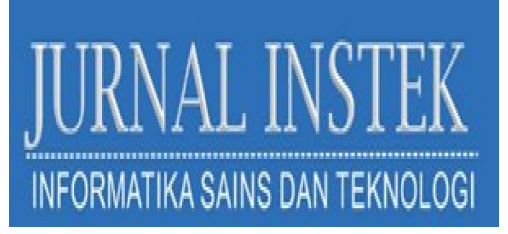

Volume 5 Nomor. 1, April 2020

P-ISSN : 2541-1179, E-ISSN : 2581-1711

Ojs :http://journal.uin-alauddin.ac.id/index.php/instek/index

Email : instek@uin-alauddin.ac.id

\title{
PEMANFAATAN BIG DATA PADA KONSEP SMART CITY : KAJIAN PUSTAKA
}

\author{
SRI KHAERAWATI NUR \\ Magister Teknik Informatika, Fakultas Teknologi Industri, Universitas Islam \\ Indonesia, Jalan Kaliurang Km. 14.5, Yogyakarta 55584, Indonesia \\ E-mail : srikhaerawatinur@gmail.com
}

\begin{abstract}
ABSTRAK
Konsep mengelola kota dengan pemanfaatan Teknologi Informasi dan Komunikasi (TIK) yang saat ini dikenal dengan smart city. Pesatnya kemajuan teknologi menjadi tantangan pengelola kota untuk bertransformasi. Dibutuhkan solusi yang tepat untuk mendukung infrastruktur teknologi yang digunakan. Penggunan big data pada teknologi smart city merupakan salah satu cara yang dapat digunakan untuk menyelesaikan tantangan yang dihadapi. Big data dapat mengelola sumber daya secara efesien. Metode yang digunakan pada penelitian ini adalah sebuah kajian pustaka terkait pemanfaatan big data pada smart city. Penelitian ini menunjukkan beberapa model analitik yang sering digunakan dalam analisis big data pada smart city. Hal ini memungkinkan untuk solusi berbagai komponen di kota cerdas. Hasil penelitian ini menunjukkan potensi ataupun manfaat pada seluruh komponen smart city.
\end{abstract}

\section{Kata kunci : Analytics, Big Data, Smart City, Teknologi Informasi}

\section{PENDAHULUAN}

Konsep 'kota cerdas' telah cukup popular pada area kebijakan dalam beberapa tahun terakhir (Caragliu, Bo, \& Nijkamp, 2009). Kota cerdas adalah kota yang mampu menerapkan fleksibilitas, transformabilitas, sinergi, dan individualitas (Giffinger, 2007). Fokus utamanya tampak pada peran infrastruktur Teknologi Infromasi dan Komunikasi (selanjutnya disingkat TIK). Meskipun banyak penelitian juga telah dilakukan pada peran manusia / pendidikan, sosial lingkungan sebagai pendorong penting pertumbuhan sebuah kota maju.

Salah satu tantangan dalam penerapan smart city adalah data yang ada di lingkungan pemerintahan sebuah kota belum dimanfaatkan secara maksimal, sehingga integrasi data masih sulit dilakukan (Supangat, 2018). Integrasi data menjadi penting 


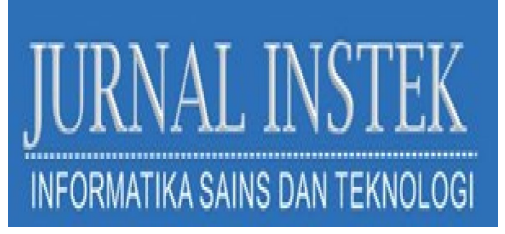

Volume 5 Nomor. 1, April 2020

P-ISSN : 2541-1179, E-ISSN : 2581-1711

Ojs :http://journal.uin-alauddin.ac.id/index.php/instek/index

Email : instek@uin-alauddin.ac.id

karena data dan informasi adalah komponen utama dalam pengambilan keputusan. Hal ini dapat diatasi dengan salah satu cara yaitu pemanfaatan big data.

Didorong oleh pertumbuhan TIK yang berkembang pesat dan memasuki era yang disebut big data. Berbekal data dengan volume yang sangat besar, kota dapat diubah secara dramatis dalam mengembangkan kota pintar (Wu et al., 2018). Meskipun tidak memiliki ketetapan tentang definisi big data, namun dapat disimpulkan big data mengacu pada 3 V's (Gartner, n.d.) yaitu volume, variety, dan velocity yang menekankan pada sejumlah besarnya data, format rekaman data, dan kecepatan menghasilkan data. Big data memberikan peluang besar untuk mengidentifikasi korupsi, kriminal, tantangan dan ancaman serta mengambil keputusan di masa depan.

Tujuan dari penelitian ini adalah untuk mengetahui bagaimana big data dapat dimanfaatkan sebagai salah satu faktor penting dalam membangun konsep smart city. Dengan melakukan kajian terhadap penelitian-penelitian sebelumnya, maka pertanyaan penelitian pada artikel ini adalah bagaimana pemanfaatan big data pada konsep smart city dan apa saja model analitik yang paling sering digunakan dalam pengembangannya.

\section{METODOLOGI PENELITIAN}

Penelitian yang dilakukan berupa kajian (literature review) atau studi pustaka terhadap beberapa artikel ilmiah yang berkaitan dengan pemanfaatan big data pada implementasi smart city. Alur atau tahapan pada sebuah penelitian dibutuhkan agar dapat tersusun secara sistematis. Adapun alur pada penelitian ini digambarkan pada Gambar 1.

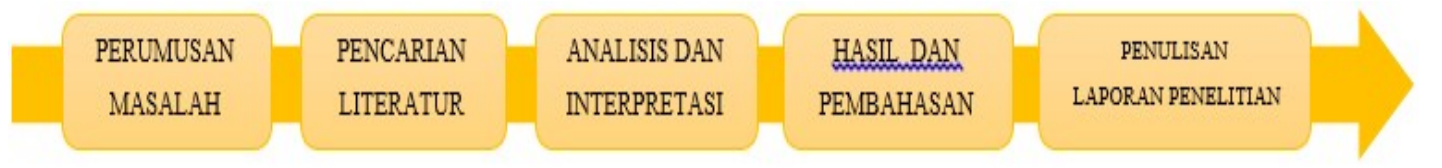

Gambar 1. Alur Penelitian

Pada Gambar 1, terlihat bahwa alur penelitian ini terdiri atas 5 (lima) langkah pokok. Penelitian dimulai dengan penelusuran masalah yang akan dijadikan topik pembahasan. Selanjutnya adalah melakukan kajian pustaka yang berhubungan dengan subyek penelitian. Pada tahapan ini peneliti melakukan penelitian berupa kajian pustaka dengan mempelajari penelitian yang sejenis dan sebelumnya pernah dilakukan oleh 
peneliti lainnya. Tujuannya ialah agar mendapatkan informasi terkait topik penelitian yang telah ditentukan. Dengan penelusuran tersebut maka akan diketahui gambaran penelitian yang telah dilakukan dan berkaitan erat dengan pemanfaatan big data pada konsep smart city. Hasil penelitian ini juga didasari beberapa hal yang perlu diketahui terlebih dahulu dan berkaitan dengan pencarian informasi, yaitu konsep smart city dan konsep big data secara umum.

\section{A. Konsep Smart City}

Sebagai konsep yang dikenal secara populer tetapi digunakan dengan nama yang berbeda dan dalam keadaan yang berbeda, berbagai varian konseptual yang dihasilkan mengganti kata smart dengan kata alternatif lainnya. Beberapa definisi smart city pada Tabel 1 telah dikemukakan dan diadopsi baik dalam penggunaan praktis maupun akademik.

Tabel 1. Definisi Smart City

\begin{tabular}{cl}
\hline Peneliti & \multicolumn{1}{c}{ Definisi } \\
\hline $\begin{array}{c}\text { Giffinger } \\
(2007)\end{array}$ & $\begin{array}{l}\text { Kota yang berkinerja baik dengan cara pandang ke depan dalam bidang } \\
\text { ekonomi, masyarakat, pemerintahan, transportasi, lingkungan, dan } \\
\text { kegiatan warga negara yang mandiri. }\end{array}$ \\
\hline Hall et al. & $\begin{array}{l}\text { Kota yang memantau dan mengintegrasikan semua infrastruktur, } \\
\text { merencanakan kegiatan pemeliharaan yang preventif, dan memantau } \\
\text { aspek keamanan sambil memaksimalkan layanan kepada warganya. }\end{array}$ \\
\hline Chen & $\begin{array}{l}\text { Kota yang memanfaatkan kemampuan komunikasi dan sensor yang } \\
\text { dimasukkan ke infrastruktur kota untuk mengoptimalkan seluruh } \\
\text { infrastruktur yang mendukung kehidupan sehari-hari }\end{array}$ \\
\hline $\begin{array}{c}\text { Caragliu et } \\
\text { al. (2009) }\end{array}$ & $\begin{array}{l}\text { Kota cerdas yang berinvestasi dengan seluruh sumber daya termasuk } \\
\text { infrastruktur tradisional dan modern / TIK dengan pengelolaan SDA yang } \\
\text { efektif melalui pengelolaan yang bijaksana. }\end{array}$ \\
\hline
\end{tabular}

Giffinger (2007) mengidentifikasi enam komponen utama smart city yaitu smart environment, smart economy, smart governance, smart mobility, smart living dan smart people. Melalui 6 komponen ini Giffinger (2007) melakukan pengukuran terhadap kotakota yang ada di Eropa. Model inipun telah menjadi umum digunakan di negara maju 


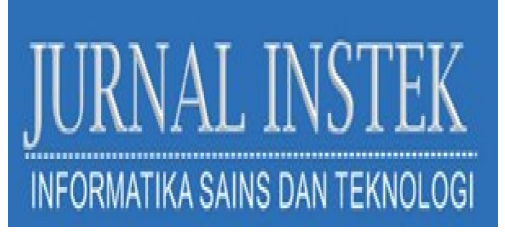

Volume 5 Nomor. 1, April 2020

P-ISSN : 2541-1179, E-ISSN : 2581-1711

Ojs :http://journal.uin-alauddin.ac.id/index.php/instek/index

Email : instek@uin-alauddin.ac.id

termasuk di Indonesia dan dalam pengembangan smart city eropa berdasarkan pengembangan eropa 2020.

Setiap dimensi ini dapat diadopsi oleh pemerintah kota/provinsi untuk disesuaikan dan dimodifikasi sesuai dengan struktur, budaya dan masyarakatnya. Beberapa kota di Indonesia juga telah memulai konsep smart city ini dengan memanfaatkan teknologi sebagai enabler. Teknologi merupakan salah satu kunci yang dapat digunakan untuk mengetahui sejauh mana kesiapan pemerintah dalam penerapan konsep smart city.

\section{B. Konsep Big Data}

Konsep big data mencakup kumpulan data dengan ukuran di luar kemampuan alat perangkat lunak yang biasa digunakan untuk menangkap, menyimpan, mengelola, dan memproses data (Kataria \& Mittal, 2014). Konsep big data telah didefinisikan melalui model 3V, yang didefinisikan pada tahun 2001 oleh Laney (2001). Selanjutnya, Gartner (n.d.) memperbarui definisi big data sebagai :

- Volume : aliran data yang masuk dan volume data kumulatif.

- Velocity : merepresentasikan kecepatan data yang digunakan untuk mendukung interaksi dan dihasilkan oleh interaksi

- Variety: menandakan berbagai format data dan struktur data yang tidak kompatibel dan tidak konsisten.

Big data memiliki potensi untuk membantu organisasi meningkatkan pelayanan dan membuat keputusan yang lebih cepat dan lebih cerdas. Berbagai data dikumpulkan dari sejumlah sumber termasuk email, perangkat seluler, aplikasi, basis data, dan sarana lainnya. Data ini diformat, dimanipulasi, disimpan dan kemudian dianalisis, sehingga dapat membantu organisasi untuk meningkatkan layanan. Big data memiliki beberapa komponen utama yang telah dirincikan oleh Manyika, et al. (2011) diantaranya teknik untuk menganalisis data seperti machine learning, dan NLP (Natural Language Processing), teknologi seperti BI (Business Intelligence), Cloud Computing, dan database serta visualisasi seperti bagan, grafik, dan tampilan data lainnya. 


\section{HASIL DAN PEMBAHASAN}

Big data memiliki potensi besar untuk meningkatkan layanan kota pintar. Hal ini memungkinkan solusi untuk transportasi yang efisien, keamanan publik, kesehatan masyarakat dengan pemanfaatan dari solusi TIK berbasis big data. Pada tabel 2, dijabarkan beberapa penelitian terkait pemanfaatan big data pada implementasi smart city. Pencarian artikel dilakukan di beberapa situs untuk mengakses jurnal nasional maupun internasional. Selanjutnya, dilakukan pengkajian secara menyeluruh agar didapatkan informasi terkait dengan topik penelitian yang dilakukan.

Pada Tabel 2 dijabarkan beberapa penelitian yang telah dilakukan pada aspek pemanfaatan big data pada konsep smart city. Hal ini membuktikan bahwa penerapan teknologi big data menjadi penting dalam pengembangan sebuah kota untuk menjadi lebih baik. Mulai dari masalah ekonomi, sosial bahkan dalam dunia kesehatan sangat membantu mendiagnosis kondisi pasien, menemukan pola dan mampu mengidentifikasi risiko dan peluang yang juga mungkin terjadi di masa depan.

Tabel 2. Contoh Pemanfaatan Big Data pada Dimensi Smart City

\begin{tabular}{|c|c|c|c|}
\hline $\begin{array}{l}\text { Komponen } \\
\text { Smart City }\end{array}$ & $\begin{array}{l}\text { Pemanfaatan Big Data } \\
\text { pada Smart City }\end{array}$ & $\begin{array}{c}\text { Model } \\
\text { Analitik }\end{array}$ & Peneliti \\
\hline \multirow[t]{3}{*}{$\begin{array}{c}\text { Smart } \\
\text { Economy }\end{array}$} & $\begin{array}{l}\text { - Meningkatkan daya saing dengan } \\
\text { menganalisa perilaku konsumen } e \text { - } \\
\text { commerce; }\end{array}$ & $\begin{array}{l}\text { Predictive } \\
\text { Analytics }\end{array}$ & $\begin{array}{l}\text { Shao \& Yao } \\
\quad(2018)\end{array}$ \\
\hline & $\begin{array}{l}\text { - Mengulas online review pada bisnis } \\
\text { perhotelan dan pariwisata }\end{array}$ & $\begin{array}{l}\text { Social Media } \\
\text { Analytics } \\
\text { Predictive }\end{array}$ & $\begin{array}{l}\text { Xiang et al. } \\
\text { (2017) }\end{array}$ \\
\hline & $\begin{array}{l}\text { - Mendukung layanan sharing } \\
\text { economy berbasis IoT dengan } \\
\text { Infratsruktur AI. }\end{array}$ & Analytics & $\begin{array}{l}\text { Hassanain et } \\
\text { al. (2019) }\end{array}$ \\
\hline \multirow[t]{3}{*}{ Smart Mobility } & $\begin{array}{l}\text { - Mengidentifkasi wilayah dengan } \\
\text { tuntutan mobilitas yang tinggi / } \\
\text { traffic flow prediction; }\end{array}$ & $\begin{array}{l}\text { Predictive } \\
\text { Analytics }\end{array}$ & $\begin{array}{l}\text { Wang et al. } \\
\text { (2016), Li et } \\
\text { al. (2017) }\end{array}$ \\
\hline & $\begin{array}{l}\text { - Menganalisis data sistem } \\
\text { transportasi dan distribusi yang } \\
\text { dibuat oleh Global Positioning }\end{array}$ & $\begin{array}{l}\text { Predictive } \\
\text { Analytics }\end{array}$ & $\begin{array}{l}\text { Niu et al. } \\
\text { (2015), } \\
\text { Mehmood \& }\end{array}$ \\
\hline & $\begin{array}{l}\text { System (GPS) untuk menemukan } \\
\text { rute tercepat. }\end{array}$ & & Graham (2015) \\
\hline \multirow[t]{2}{*}{ Smart People } & $\begin{array}{l}\text { - Melakukan analitik pada media } \\
\text { sosial untuk mengetahui trend / } \\
\text { situasi terkini }\end{array}$ & $\begin{array}{l}\text { Sosial Media } \\
\text { Analytics }\end{array}$ & $\begin{array}{l}\text { Roessobiyatno } \\
\text { et al. (2016) }\end{array}$ \\
\hline & & $\begin{array}{l}\text { Predictive } \\
\text { Analytics }\end{array}$ & $\begin{array}{l}\text { Yanchun \& } \\
\text { Lin (2017) }\end{array}$ \\
\hline
\end{tabular}


- Optimalisasi pariwisata terhadap pengunjung berdasarkan perkembangan ekonomi

Predictive

Analytics

Fujimura et al.

(2014)

- Melakukan analitik terhadap perilaku pelajar untuk meningkatkan kualitas belajar

\begin{tabular}{|c|c|c|c|}
\hline Smart Living & $\begin{array}{l}\text { - Meningkatkan layanan kesehatan } \\
\text { berbasis mobile healthcare / } \\
\text { electronic health record (seperti } \\
\text { respon darurat dan diagnosis } \\
\text { penyakit); } \\
\text { - Memfasilitasi perencanaan kota } \\
\text { dengan menggunakan berbagai jenis } \\
\text { penyebaran sensor }\end{array}$ & $\begin{array}{l}\text { Predictive } \\
\text { Analytics }\end{array}$ & $\begin{array}{l}\text { M. Chen et al } \\
\text { (2016), } \\
\text { Istepanian \& } \\
\text { Al-Anzi } \\
\text { (2018) } \\
\text { Stanivlas et al. } \\
\text { (2015) }\end{array}$ \\
\hline $\begin{array}{c}\text { Smart } \\
\text { Governance }\end{array}$ & $\begin{array}{l}\text { - Memprediksi dan mencegah properti } \\
\text { / hunian yang kosong, menyediakan } \\
\text { sumber single information untuk } \\
\text { warga kepada lembaga pemerintah } \\
\text { - Penentuan kebijakan menggunakan } \\
\text { geosocial media data }\end{array}$ & $\begin{array}{c}\text { Social Media } \\
\text { Analytics }\end{array}$ & $\begin{array}{l}\text { Kim et al. } \\
(2014)\end{array}$ \\
\hline $\begin{array}{c}\text { Smart } \\
\text { Environment }\end{array}$ & $\begin{array}{l}\text { - Proyek smart grid yang diterapkan } \\
\text { menggunakan infrastruktur cyber } \\
\text { komputasi untuk memastikan } \\
\text { sumber energi yang efisien dan } \\
\text { andal; } \\
\text { - Menggunakan big data untuk } \\
\text { meningkatkan respons krisis dan } \\
\text { ketahanan bencana. }\end{array}$ & $\begin{array}{l}\text { Predictive } \\
\text { Analytics }\end{array}$ & $\begin{array}{l}\text { Yang, Su, \& } \\
\text { Chen (2017) }\end{array}$ \\
\hline
\end{tabular}

Secara keseluruhan dari hasil studi pustaka yang dilakukan terkait dengan metode analitik yang digunakan, ditemukan bahwa 75\% penelitian tersebut melakukan predictive analytics, hal ini dapat dilihat pada Gambar 2. Skema tersebut menandakan bahwa fokus penelitian terkait pemanfataan big data pada smart city masih dilakukan dengan berbagai teknik statistik dari pemodelan prediktif (predictive analytics). Enam komponen smart city secara keseluruhan telah dihubungkan dengan pemanfaatan big data.

Seiring berkembangnya teknologi di dunia maya, tren membaca pola perilaku melalui media sosial mulai dimanfaatkan oleh Pemerintah / Organisasi untuk mendapatkan informasi yang lebih cepat dan real-time. Dapat dilihat pada skema penelitian di atas, social media analytic pada smart city digunakan pada komponen 
smart economy, smart people dan smart governance. Sosial media analytics masih menjadi bahan analisis pemerintah selama beberapa tahun terakhir karena dapat langsung mengetahui tren atau kondisi masyarakatnya (real-time), apalagi jika dikaitkan dengan masalah penyebaran berita hoax.

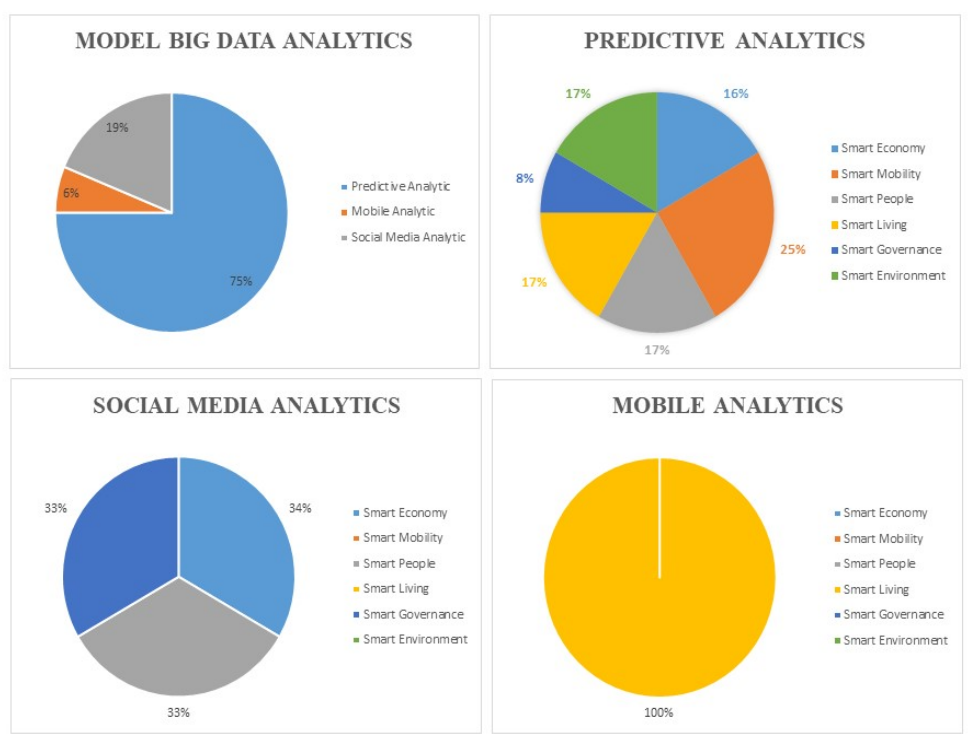

Gambar 2. Skema Penelitian Terkait Model Analytics pada Smart City

Pada smart economy, biasanya dilakukan untuk mengetahui testimoni atau review pelanggan yang dituliskan pada akun media sosial mereka. Data dari media sosial tersebut dikumpulkan dan dianalisa untuk menjadi sebuah bahan pertimbangan. Untuk smart people, analitik social media dapat digunakan sebagai jalan kepada pemerintah untuk memberikan masukan atau kritik terhadap layanan dan pemerintah akan merespon dengan cepat dengan memberi tanggap dari hasil analisis media sosial. Sedangkan untuk mobile analytics pada komponen smart city masih berpeluang cukup besar untuk dilakukan penelitian atau pengembangan model analytic. Sesuai dengan hasil kajian, pemanfaatan mobile analytics masih digunakan untuk pemecahan masalah khususnya terkait kesehatan yang masuk dalam komponen smart living. Tidak menutup kemungkinan terdapat penelitian dengan aspek yang sama namun berada pada komponen yang berbeda. 


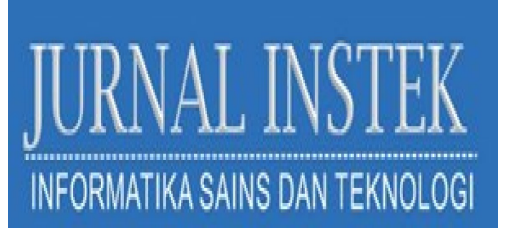

Volume 5 Nomor. 1, April 2020

P -ISSN : 2541-1179, E-ISSN : 2581-1711

Ojs :http://journal.uin-alauddin.ac.id/index.php/instek/index

Email : instek@uin-alauddin.ac.id

\section{PENUTUP}

\section{A. Kesimpulan}

Seiring dengan berkembangnya tren big data di berbagai sektor kehidupan, big data memiliki potensi besar untuk meningkatkan layanan masyarakat dengan dukungan infrastruktur teknologi pada seluruh komponen smart city. Hasil kajian pustaka yang telah dilakukan menunjukkan predictive analytics masih sering digunakan dalam membuat prediksi tentang kondisi yang mungkin terjadi. Selain predictive analytics, pendekatan analitik big data lainnya juga telah banyak digunakan sebagai pendekatan yang sesuai dengan kebutuhan analisis yaitu social media analytics dan mobile analytics.

\section{B. Saran}

Penelitian ini diharapkan dapat memberikan wawasan baru ataupun menjadi referensi tambahan dalam pengembangan maupun penelitian terkait pemanfaatan big data pada smart city. Pada penelitian selanjutnya diharapkan dapat melakukan kajian dengan lebih banyak penelitian dan dengan model analitik yang lebih variatif.

\section{DAFTAR PUSTAKA}

Caragliu, A., Bo \& Nijkamp, P. (2009). Smart cities in Europe, 45-59.

Chen, M., Ma, Y., Song, J., Lai, C. F., \& Hu, B. (2016). Smart Clothing: Connecting Human with Clouds and Big Data for Sustainable Health Monitoring. Mobile Networks and Applications, 21(5), 825-845.

Chen, T. M. (2010). Smart Grids, Smart Cities Need Better Networks, 2-3.

Fujimura K; Ogata, H; Okubo, F; Shimada, A; Yamada, M; Yin, C; N. K. (2014). Smart Phone based Data Collecting System for Analyzing Learning Behaviors. 575-577.

Gartner. (n.d.). What Is Big Data? - Gartner IT Glossary - Big Data. Retrieved January 2, 2019, from https://www.gartner.com/it-glossary/big-data/

Giffinger, R. (2007). Smart cities Ranking of European medium-sized cities. October, 16(October), 13-18.

Hall, R. E., Braverman, J., Taylor, J., \& Todosow, H. (2000). The Vision of A Smart 


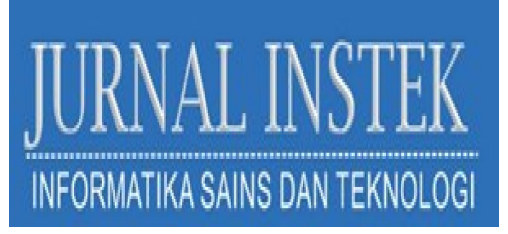

Volume 5 Nomor. 1, April 2020

P-ISSN : 2541-1179, E-ISSN : 2581-1711

Ojs :http://journal.uin-alauddin.ac.id/index.php/instek/index

Email : instek@uin-alauddin.ac.id

City. https://doi.org/10.1017/CBO9781107415324.004

Hassanain, E., Rahman, M. A., Alhamid, M. F., Hossain, M. S., Guizani, M., \& Rashid, M. M. (2019). Blockchain and IoT-based Cognitive Edge Framework for Sharing Economy Services in a Smart City. IEEE Access, PP(c), 1-1. https://doi.org/10.1109/access.2019.2896065

Istepanian, R. S. H., \& Al-Anzi, T. (2018). m-Health 2.0: New perspectives on mobile health, machine learning and big data analytics. Methods, 151(May), 34-40. https://doi.org/10.1016/j.ymeth.2018.05.015

Kataria, M., \& Mittal, P. (2014). International Journal of Computer Science and Mobile Computing BIG DATA: A Review. International Journal of Computer Science and Mobile Computing, 3(7), 106-110.

Kim, B. G., Trimi, S., \& Chung, J. (2014). Big data application in government sector. https://doi.org/10.1145/2500873

Laney, D. (2001). Application Delivery Strategies from META Group. META Delta, 949(February 2001), 4. https://doi.org/10.1016/j.infsof.2008.09.005

Li, Y., Zhao, L., Yu, Z., \& Wang, S. (2017). Traffic Flow Prediction With Big Data : A Learning Approach Based on SIS-Complex Networks, 16(2), 550-554.

Manyika, J., Chui, M., B., B., Bughin, J., Dobbs, R., Roxburgh, C., \& Hung Byers, A. (2011). Big data: The next frontier for innovation, competition and productivity.

Mehmood, R., \& Graham, G. (2015). Big Data Logistics: A health-care Transport Capacity Sharing Model. Procedia Computer Science, 64, 1107-1114.

Niu, X., Zhu, Y., Cao, Q., Zhang, X., Xie, W., \& Zheng, K. (2015). An Online-TrafficPrediction Based Route Finding Mechanism for Smart City. International Journal of Distributed Sensor Networks, 2015.

Roessobiyatno, Anggoro, T. P., Nainggolan, B., \& Purwandesi, E. (2016). Social media analysis supporting smart city implementation (Practical study in Bandung district). 2016 International Conference on ICT for Smart Society, ICISS 2016, (July), 80-86. https://doi.org/10.1109/ICTSS.2016.7792853

Shao, F., \& Yao, J. (2018). The Establishment of Data Analysis Model about ECommerce's Behavior Based on Hadoop Platform. Proceedings - 3rd International Conference on Intelligent Transportation, Big Data and Smart City, ICITBS 2018, 2018-Janua, 436-439.

Stanivlas, S., Bojic, I., \& Belyi, A. (2015). Scaling of City Attractiveness for Foreign 


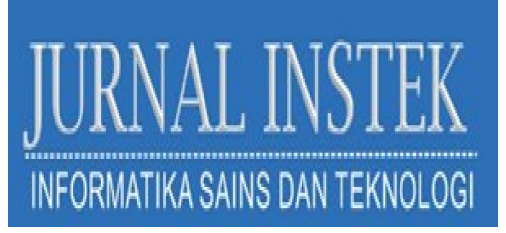

Volume 5 Nomor. 1, April 2020

P-ISSN : 2541-1179, E-ISSN : 2581-1711

Ojs :http://journal.uin-alauddin.ac.id/index.php/instek/index

Email : instek@uin-alauddin.ac.id

Visitors through Big Data of Human Economical and Social Media Activity Accessed Senseable City Lab : Massachusetts Institute of Technology

Supangat, S. H. (2018). Smart Province. https://doi.org/http://knsi2018.info/wpcontent/uploads/2018/03/POWER-POINT-PROF.-SUHONO-SMART-

PROVINCE.pdf

Wang, Y., Ram, S., Currim, F., Dantas, E., \& Sabóia, L. A. (2016). A big data approach for smart transportation management on bus network. IEEE 2nd International Smart Cities Conference: Improving the Citizens Quality of Life, ISC2 2016 Proceedings, 0-5. https://doi.org/10.1109/ISC2.2016.7580839

Wu, Y., Zhang, W., Shen, J., Mo, Z., \& Peng, Y. (2018). Smart city with Chinese characteristics against the background of big data: Idea, action and risk The increase of Chinese urban population

Xiang, Z., Du, Q., Ma, Y., \& Fan, W. (2017). A comparative analysis of major online review platforms: Implications for social media analytics in hospitality and tourism. Tourism Management, 58, 51-65.

Yanchun, L., \& Lin, L. (2017). The optimization design of pro-poor tourism information system in sichuan area with introduction of big data analysis. Proceedings - 2016 International Conference on Intelligent Transportation, Big Data and Smart City, ICITBS 2016, 3, 482-485.

Yang, C., Su, G., \& Chen, J. (2017). Using big data to enhance crisis response and disaster resilience for a smart city. 2017 IEEE 2nd International Conference on Big Data Analysis, ICBDA 2017, 504-507.

Zhou, K., Fu, C., \& Yang, S. (2016). Big data driven smart energy management: From big data to big insights. Renewable and Sustainable Energy Reviews, 56(2016), 215-225. https://doi.org/10.1016/j.rser.2015.11.050

Zook, M. (2017). Crowd-sourcing the smart city: Using big geosocial media metrics in urban governance. Big Data \& Society, 4(1), 205395171769438. https://doi.org/10.1177/2053951717694384 